\title{
Interstitial Deletion of 2q22.2q22.3 Involving the Entire ZEB2 Gene in a Case of Mowat-Wilson Syndrome
}

\author{
Khaled Refaat ${ }^{a} \quad$ Nivine Helmy $^{a}$ Mohamed Elawady ${ }^{c}$ Mona El Ruby ${ }^{b}$ \\ Alaa Kamel $^{\mathrm{a}}$ Mona Mekkawy $^{\mathrm{a}}$ Engy Ashaat ${ }^{\mathrm{b}}$ Ola Eid $^{\mathrm{a}}$ Amal Mohamed $^{\mathrm{a}}$ \\ Mervat Radyc \\ aDivision of Human Genetics and Genome Research, Department of Human Cytogenetics, National Research Centre, \\ Cairo, Egypt; ${ }^{b}$ Department of Clinical Genetics, National Research Centre, Cairo, Egypt; 'Department of Community \\ Medicine and Public Health, Faculty of Medicine, Ain Shams University, Cairo, Egypt
}

\section{Keywords}

Mowat-Wilson syndrome $\cdot$ ZEB2 $\cdot$ Array CGH · Syndromic congenital heart disease $\cdot$ Hirschsprung disease

\begin{abstract}
Mowat-Wilson syndrome (MWS) is a rare autosomal dominant syndrome characterized by dysmorphic features, mental retardation, and congenital heart disease (CHD). MWS results from microdeletions of chromosome 2 q23 or de novo SNVs involving the ZEB2 gene. Here, we report on an Egyptian MWS patient diagnosed by chromosomal microarray (CMA). A 1-year-old male child was referred to the CHD clinic, National Research Centre, presenting with dysmorphic features and CHD. The patient was referred to the human cytogenetics department for cytogenetic analysis and for screening of subtelomere rearrangements and microdeletion loci, using MLPA, and all revealed normal results. CMA revealed an interstitial $2.27-\mathrm{Mb}$ microdeletion in chromosome $2 q$, involving the entire ZEB2 gene and other genes. This study emphasizes the significance of CMA in the detection of microdeletions/microduplications and as a screening
\end{abstract}

tool in cases presenting with CHD and extracardiac manifestations. MWS should be suspected in patients presenting with the characteristic facial dysmorphism, developmental delay, seizures, Hirschsprung disease, and congenital heart anomalies, especially those involving the pulmonary arteries or pulmonary valves. It is recommended to include the ZEB2 locus in the MLPA microdeletions probes.

(c) 2021 S. Karger AG, Basel

\section{Introduction}

Mowat-Wilson syndrome (MWS; OMIM 235730), a rare autosomal dominant multiple congenital anomaly syndrome, is present in 1: 50,000-70,000 individuals [Mowat and Wilson, 2010]. It is characterized by intellectual disability (ID), facial dysmorphism in addition to congenital anomalies [Mowat et al., 1998]. Developmental disorder is the main presenting feature with a wide spectrum of clinically heterogeneous features. Characteristic dysmorphic facial features include microcephaly, square-shaped face, a prominent narrow triangular chin, karger@karger.com

(C) 2021 S. Karger AG, Basel

www.karger.com/msy

Karger ${ }^{\prime}=$
Khaled Refaat

Human Genetics and Genome Research Division

Human Cytogenetics Department, National Research Centre

33 El Buhouth Street, El-Dokki, Cairo 12622 (Egypt)

Dr.khaled.refaat@gmail.com 
hypertelorism with deep-set large eyes, broad nasal bridge, saddle nose with a prominent rounded nasal tip, and open mouth with everted or full lower lip, and posteriorly rotated ears and big uplifted ear lobes with a central depression [Garavelli and Mainardi, 2007].

The patients manifest moderate to severe ID, epilepsy and congenital malformations that could include Hirschsprung disease (HSCR) and genital anomalies, specifically hypospadias in males [Garavelli and Mainardi, 2007].

More than half of the patients with MWS are born with Hirschsprung disease that mainly causes the patients to suffer from severe constipation, intestinal blockage, and enlargement of the colon [Ivanovski et al., 2018]. Also chronic constipation is a frequent manifestation seen in patients not diagnosed with Hirschsprung disease [Ishihara et al., 2005].

Congenital heart disease (CHD) has been documented in $45 \%$ of the cases in the form of patent ductus arteriosus (PDA), ventricular septal defect (VSD), atrial septal defect (ASD), Fallot tetralogy, pulmonary atresia with or without stenosis, aortic coarctation, bicuspid aortic valve, and aortic valve stenosis [Amiel et al., 2002]. Agenesis of the corpus callosum (ACC) and eye defects were also reported [Yamada et al., 2001]. Mowat et al. [1998] proposed that MWS results from microdeletion in $2 \mathrm{q} 22 \mathrm{q} 23$ or due to a de novo mutation of a gene present in this region.

Through studies of de novo translocations involving a breakpoint at $2 \mathrm{q} 22$ in individuals affected by the syndrome, 2 study groups identified a gene, SIP1, which is deleted by chromosomal rearrangement (abbreviated now as ZEB2; OMIM\# 605802). Further analysis of other patients revealed heterozygous frameshift mutations affecting the ZEB2 gene causing early truncation of the protein [Cacheux et al., 2001; Wakamatsu et al., 2001].

The actual prevalence of MWS is undetermined, but it seems that it is underestimated. MWS is a relatively newly described syndrome with a wide phenotypic variability, which makes the diagnosis difficult, specifically in patients without HSCR [Zweier et al., 2002]. Since the first delineation by Mowat et al. [1998], more than 300 cases with ZEB2 mutations, deletions or cytogenetic abnormalities have been stated mainly from Northern Europe, Italy, Australia, and the United States, and more than 100 mutations were reported [Wakamatsu et al., 2001; Ghoumid et al., 2013; Paz et al., 2015; Ivanovski et al., 2018].

Herein, we describe the first Egyptian MWS patient diagnosed by chromosomal microarray (CMA).

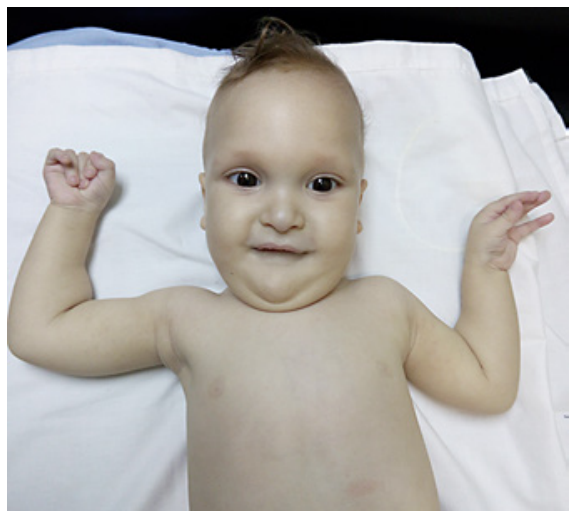

Fig. 1. Facial features of our Mowat-Wilson syndrome case.

\section{Clinical Report}

The proband was a 1-year-old male child, referred to the CHD clinic, centre of scientific excellence, National Research Centre, due to respiratory distress and cyanosis. The parents reported that their child had delayed motor and mental milestones. Pedigree analysis showed negative parental consanguinity with no family history of congenital anomalies or similarly affected family members.

The child is the second of a healthy young couple, delivered by caesarean section. At birth, his weight was normal $(2.750 \mathrm{~kg})$, and cyanosis was noticed since birth. Full history was taken from the parents including developmental milestones, detailed history of cardiac symptoms, convulsions and/or other relevant symptoms.

On clinical examination the child was in respiratory distress with cyanosis, but with a pleasant smile. Full detailed examination was carried out with special emphasis on cardiac examination, craniofacial dysmorphic features, ears, nose and throat. He had peculiar dysmorphic facies in form of a long face, frontal bossing, sparse hair, microcephaly, scanty medially flared broad eyebrows, downward prominent columella with short philtrum, deep-set wide eyes, mild epicanthic fold, hypertelorism, low-set ears with everted (uplifted) lobules, pointed chin, retro micrognathia, and short neck as shown in Figure 1.

Limb examination revealed a right clenched fist with overriding fingers. Anthropometric measurements showed normal length (on mean) and failure to gain weight, his weight was $7 \mathrm{~kg}(-3.1 \mathrm{SD})$. The patient also showed microcephaly $(-3.2 \mathrm{SD})$.

Neurological examination revealed hypotonia with hyporeflexia. Brain MRI showed ACC and white matter degeneration as shown in Figure 2. EEG was normal and no epileptic focus or hyperactive spikes could be detected. Echocardiography confirmed VSD, ASD, and moderate valvular pulmonary stenosis. Pelviabdominal ultrasonography was normal.

Clinical reevaluation of the proband at age 3 years revealed the same clinical features, and his face became more elongated. Hypotonia persisted with a wide-based, unsteady gait. No convulsions were detected by the parents, and the patient had a normal bowl habit. Hearing test was normal and no eye defects could be detected. Neurodevelopmental delay, severe ID, and severe speech delay became evident clinically and by specific investigations. The patient was diagnosed with multiple congenital anomaly/intellectual disability syndrome.
Refaat/Helmy/Elawady/El Ruby/Kamel/ Mekkawy/Ashaat/Eid/Mohamed/Rady 


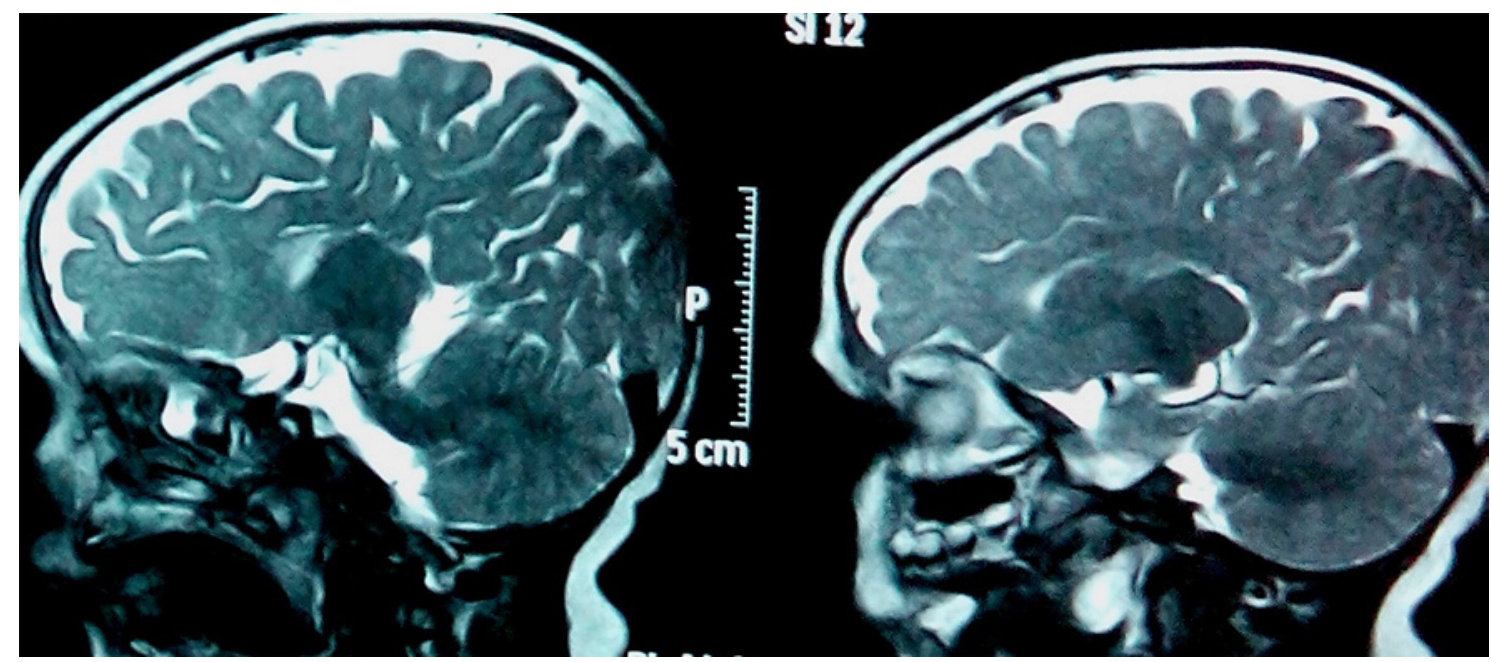

Fig. 2. Brain MRI showing agenesis of corpus callosum.

\section{Materials and Methods}

Conventional cytogenetic analysis by GTG-banding was used [Verma and Babu, 1995], and karyotype description followed the International System for Human Cytogenomic Nomenclature recommendations [ISCN, 2016].

DNA was extracted from $5 \mathrm{~mL}$ of venous blood collected in PAXgene tube using PAXgene kit (PreAnalytix, Hiden, Germany). Measurements of quality and quantity of DNA were done using the NanoDrop spectrophotometer.

MLPA assay was used as a screening test for patients with dysmorphic features, developmental delay, and CHD. It was done using 2 commercial kits: SALSA MLPA P245 microdeletion Kit and MLPA P070 subtelomere Kit.

Copy number variants (deletions, duplications) were detected by CMA over the genome using HD microchips (Affymetrix, Santa Clara, CA, USA). Through 4 days' workflow, DNA digestion, ligation, amplification, purification, fragmentation, labeling, and then loading to the microchips was performed. Hybridization was done for $16 \mathrm{~h}$ in Gene chip hybridization oven 645 (Affymetrix). The microchips were then washed and stained in fluidic station 450 (Affymetrix). Thereafter, microchips were scanned in Gene chip scanner 3000 (Affymetrix) and analyzed by the chromosome analysis suit (CHAS) software.

\section{Results}

Conventional cytogenetic analysis revealed a 46,XY normal male karyotype. MLPA revealed normal copy numbers in all subtelomeres and microdeletion loci (which does not involve the MWS locus) (Fig. 3, 4).

CMA showed an interstitial 2.27-Mb deletion of chromosome 2q22 including the entire ZEB2 gene: $\operatorname{arr}$ [hg19] 2q22.2q22.3(143375948_145653287) $\times 1$ as seen in Figure
5. Other genes were also found to be deleted in this region including HSR, VCRL2, TSE2, CMD1H, COPD, CHDS2, GTDC1, ARHGAP15, and MAFD5.

\section{Discussion}

MWS has wide variations of symptoms, ranging from typical dysmorphic features and delayed developmental milestones to that with HSCR, CHD, and a range of other congenital anomalies [Garavelli and Mainardi, 2007]. Abdalla and Zayed [2014] reported the first Egyptian MWS case conceived by intracytoplasmic sperm injection (ICSI). The patient was diagnosed clinically according to the characteristic facial gestalt of MWS, global developmental delay, severe ID with impaired speech, epilepsy, ACC, and bilateral sensorineural hearing loss as a new manifestation. However, molecular testing for ZEB2 was recommended for proper diagnosis, as it was not available according to Abdalla and Zayed [2014].

The distinctive facial features are considered the most clinically reliable feature for diagnosing those patients, the rarity of this syndrome and the phenotypic variability may seldom make it difficult to diagnose. Moreover, a change in some of the facial features tends to occur with age. In any case, the gestalt is typical at all ages [Garavelli et al., 2009]. The clinical suspect must be confirmed with molecular testing, beginning with the analysis of the ZEB2 gene, and if a variant is not detected, MLPA analysis/array CGH for microdeletions should be carried out. 


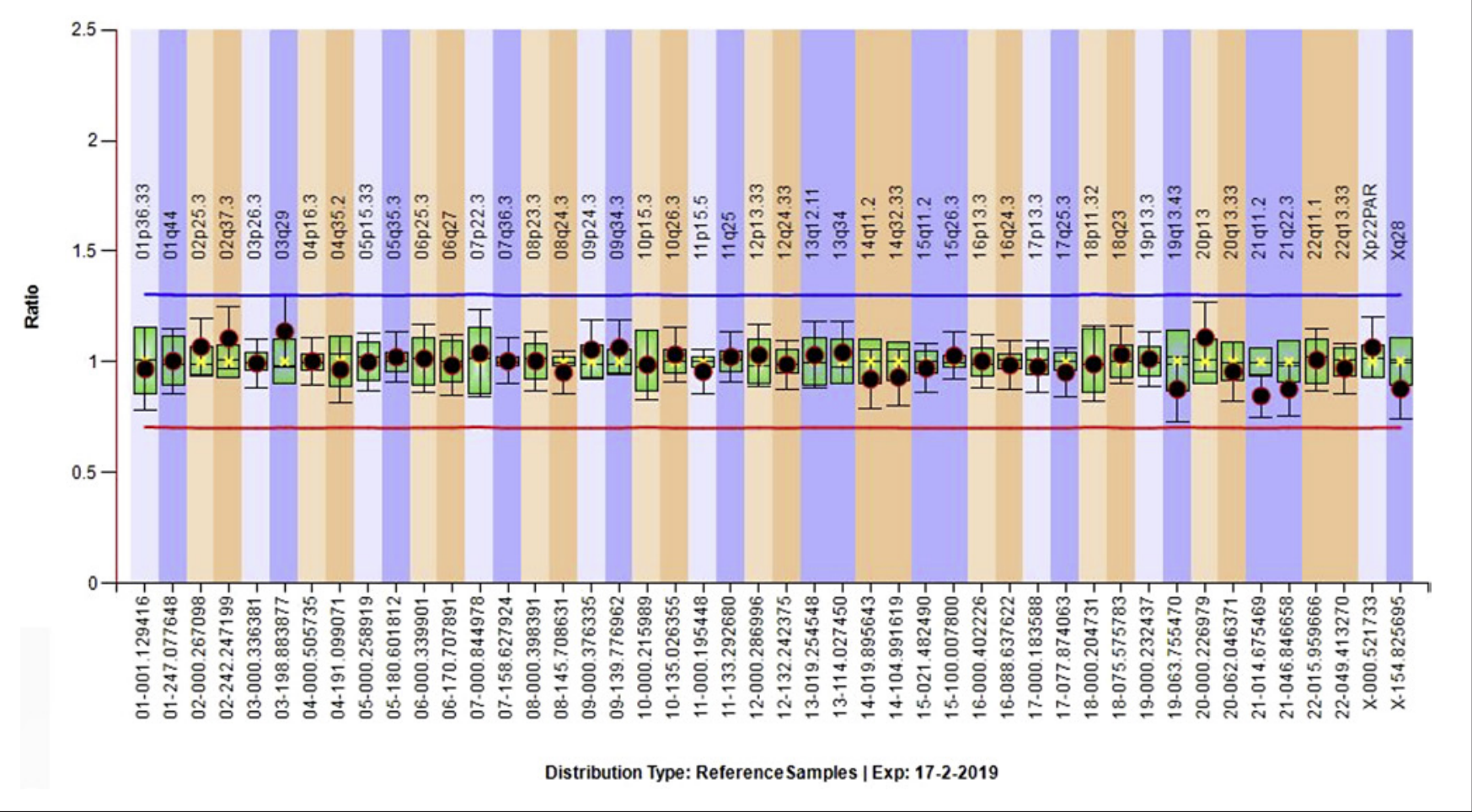

Fig. 3. MLPA ratio chart using MLPA microdeletion kit showing no copy number variation.

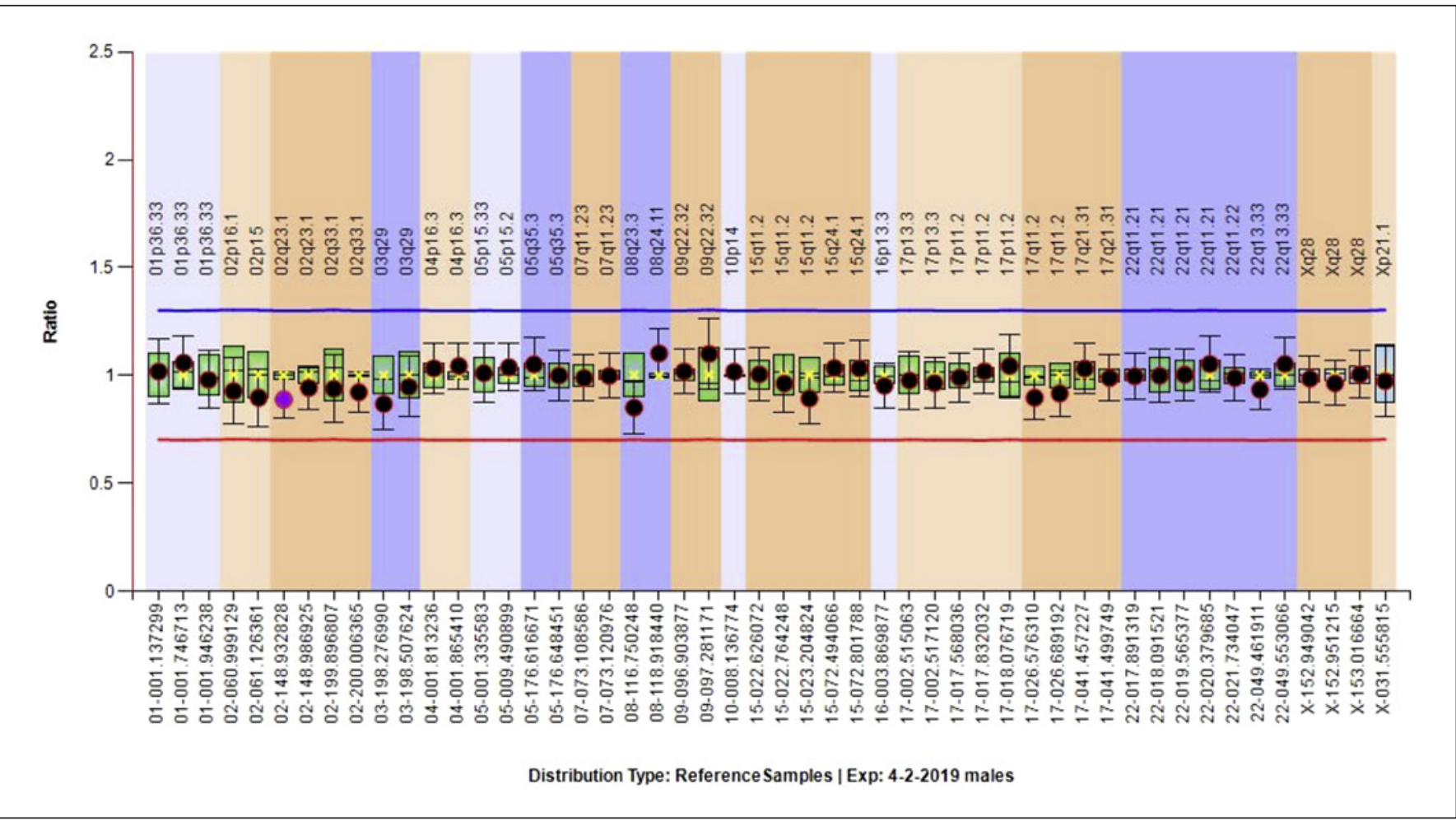

Fig. 4. MLPA ratio chart using MLPA subtelomere kit showing no copy number variation. 


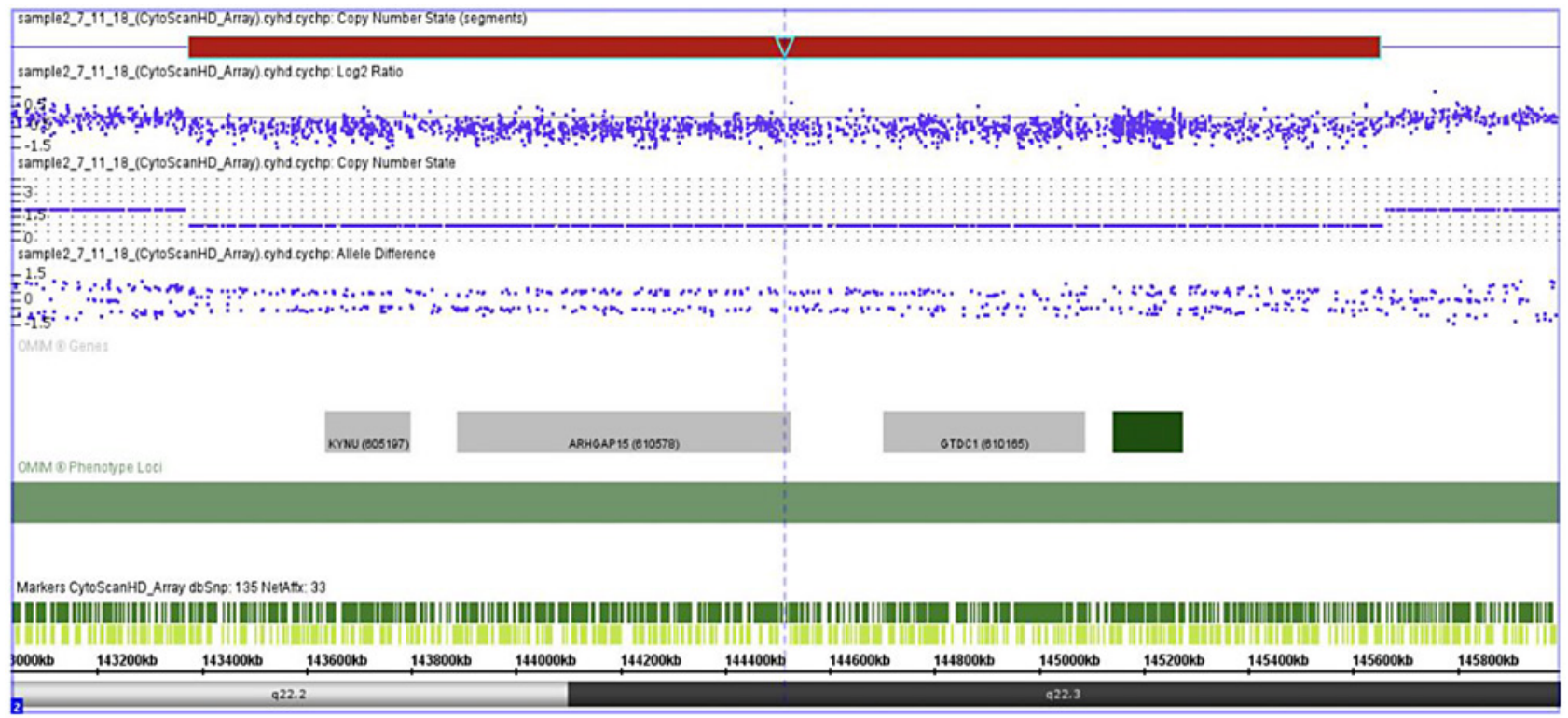

Fig. 5. Chromosomal microarray showing interstitial deletion of $2 \mathrm{q} 22.2 \mathrm{q} 22.3$ (indicated by the red bar at the top), the $\mathrm{CN}$ state $=1, \log 2=-0.45$, allele difference $=2$.

In the present study, our patient exhibited distinctive dysmorphic facial features; however, clinical presentation was at an early age and lacked HSCR, which is a common finding. He also had some atypical features, such as a clenched fist with overriding fingers, normal stature, and a normal EEG. The diagnosis was established after CMA that showed a microdeletion involving the whole ZEB2 gene.

HSCR usually manifests as severe constipation, intestinal blockage, and enlargement of the colon. It was considered the main diagnostic feature of MWS before delineation of the recognizable facial features which led to a high proportion of MWS patients with HSCR, representing $44.2 \%$ of the patients [Ivanovski et al., 2018]. Nonetheless, it is possible that the presence of HSCR is underestimated in many patients who had severe constipation, not diagnosed by rectal biopsy due to fear of complications or absence of compliance.

The variation in severity of HSCR may be caused by both variants in $Z E B 2$ and epigenetic factors [Ishihara et al., 2005]. Yoneda et al. [2002] reported a woman, who developed a late-infantile-onset of ID, severe constipation, and megacolon in adulthood without typical clinical features of MWS. The authors detected a deletion in exon 3 of the ZEB2 gene and suggested that the patient could represent an intermediate stage of severity due to partial deletion of the gene.

Mowat-Wilson Syndrome Patient due to Interstitial Deletion Involving ZEB2
Although our patient had constipation upon first evaluation, normal bowl habit was documented by his parents in the following reevaluation, which excluded HSCR clinically. Similar to our patient, many other MWS patients without HSCR but with constipation were reported constituting 26-29\% of all cases [Yamada et al., 2001; Wilson et al., 2003; Dastot-Le Moal et al., 2007; Ivanovski et al., 2018].

With the development of advanced molecular and high-throughput diagnostic techniques, more HSCR-free patients were diagnosed, and the frequency of HSCR began to decline, reflecting the importance of recognizable facial features in diagnosing those patients rather than the presence of HSCR. Ivanovski et al. [2018] reported a frequency of $30.6 \%$ of HSCR among a cohort of 87 MWS patients, while the combined frequencies of HSCR and constipation were $72 \%$.

In addition to the distinctive facial features, our patient exhibited other features consistent with loss of function of ZEB2 [Mowat et al., 2003] including severe ID, microcephaly, hypotonia, hyporeflexia, ACC, and severe congenital heart defects (Table 1).

Based on literature reviewing, all patients with MWS have moderate to severe ID and delayed developmental milestones. Hypotonia is a frequent sign detected in about $79.1 \%$ of the patients in their first years of life [Ivanovski 
Table 1. Clinical features of Mowat-Wilson syndrome

\begin{tabular}{|c|c|c|c|c|c|c|c|c|c|}
\hline & $\begin{array}{l}\text { Lurie } \\
\text { et al., } 1994 \\
(n=1)\end{array}$ & $\begin{array}{l}\text { Amiel } \\
\text { et al., } 2002 \\
(n=8)\end{array}$ & $\begin{array}{l}\text { Yamada } \\
\text { et al., 2002 } \\
(n=10)\end{array}$ & $\begin{array}{l}\text { Zweier et al., } \\
2002(n=4)\end{array}$ & $\begin{array}{l}\text { Garavelli } \\
\text { et al., } 2003 \\
(n=1)\end{array}$ & $\begin{array}{l}\text { Mowat } \\
\text { et al., 2003 } \\
(n=21)\end{array}$ & $\begin{array}{l}\text { Ivanovski } \\
\text { et al., 2018 } \\
(n=344)\end{array}$ & $\begin{array}{l}\text { Present } \\
\text { case } \\
(n=1)\end{array}$ & $\begin{array}{l}\text { Total cases } \\
(n=345)\end{array}$ \\
\hline Male/female & M & $3 / 5$ & $7 / 3$ & $4 / 0$ & M & $15 / 6$ & 183:161 & M & $184: 161$ \\
\hline Typical face & $1 / 1$ & $5 / 5$ & $5 / 5$ & $3 / 3$ & $1 / 1$ & $21 / 21$ & $100 \%$ & $1 / 1$ & $100 \%$ \\
\hline Broad eyebrows & + & + & + & + & + & + & & - & \\
\hline Deep-set eyes & + & + & + & + & + & + & & + & \\
\hline Fleshy upturned lobules & + & + & + & + & + & + & & + & \\
\hline Pointed chin & + & + & + & + & + & + & & + & \\
\hline Moderate to severe ID & $1 / 1$ & $8 / 8$ & $10 / 10$ & $4 / 4$ & $1 / 1$ & 21 & $100 \%$ & $1 / 1$ & $100 \%$ \\
\hline Seizures/abnormal EEG & $1 / 1$ & $6 / 7$ & $8 / 10$ & $3 / 4$ & $1 / 1$ & $15 / 3$ & $241 / 307(78.5 \%)$ & $0 / 1$ & $\begin{array}{l}241 / 308 \\
(78.2 \%)\end{array}$ \\
\hline Agenesis of corpus callosum & Not stated & $6 / 8$ & $3 / 4$ & $1 / 3$ & Not stated & $5 / 16$ & Not stated & $1 / 1$ & \\
\hline $\begin{array}{l}\text { Congenital heart anomaly } \\
\text { ASD } \\
\text { VSD } \\
\text { PS } \\
\text { Pulmonary artery sling }\end{array}$ & $1 / 1$ & $5 / 8$ & $3 / 10$ & $3 / 4$ & $0 / 1$ & $9 / 21$ & $193 / 332(58.1 \%)$ & $\begin{array}{l}1 / 1 \\
+ \\
+ \\
+ \\
-\end{array}$ & $\begin{array}{l}194 / 332 \\
(58.4 \%)\end{array}$ \\
\hline Hirschsprung disease & $1 / 1$ & $7 / 8$ & $4 / 10$ & $2 / 4$ & $1 / 1$ & $13 / 21$ & $148 / 335(44.2 \%)$ & $0 / 1$ & $\begin{array}{l}148 / 336 \\
(44 \%)\end{array}$ \\
\hline Microcephaly & $1 / 1$ & $7 / 7$ & $10 / 10$ & $2 / 4$ & $0 / 1$ & $16 / 20$ & $244 / 314(77.7 \%)$ & $1 / 1$ & $\begin{array}{l}245 / 315 \\
(77.8 \%)\end{array}$ \\
\hline Renal anomaly & $0 / 1$ & $2 / 4$ & Not stated & Not stated & Not stated & $6 / 16$ & $59 / 233(25.3 \%)$ & $0 / 1$ & $\begin{array}{l}59 / 234 \\
(25.2 \%)\end{array}$ \\
\hline Short stature $(<3$ rd centile $)$ & $1 / 1$ & Not stated & Not shown & $3 / 4$ & $0 / 1$ & $8 / 18$ & $70 / 151(46.4 \%)$ & $1 / 1$ & $\begin{array}{l}71 / 151 \\
(47 \%)\end{array}$ \\
\hline Genital anomalies & $0 / 1$ & $2 / 4$ & Not shown & $1 / 4$ & $1 / 1$ & $11 / 15$ & $105 / 244(43 \%)$ & $0 / 1$ & $\begin{array}{l}105 / 245 \\
(42.8 \%)\end{array}$ \\
\hline Molecular cytogenetic defect & $\begin{array}{l}\text { Interstitial deletion } \\
\text { of } 2 \mathrm{q} 22 \mathrm{q} 23 \\
\text { including the } \\
\text { entire } Z E B 2 \text { gene }\end{array}$ & $\begin{array}{l}\text { Largescale SMADIP1 } \\
\text { deletions or truncating } \\
\text { [Lurie, 1994; Garavelli } \\
\text { et al., 2003] mutations } \\
\text { in } 8 \text { of } 19 \text { patients }\end{array}$ & $\begin{array}{l}\text { ZEB2 mutation in } \\
6 \text { patients without } \\
\text { Hirschsprung } \\
\text { disease }\end{array}$ & $\begin{array}{l}\text { Direct sequencing } \\
\text { demonstrated } \\
\text { truncating } \\
Z F H X 1 B \text { mutations } \\
\text { in all } 4 \text { patients }\end{array}$ & $\begin{array}{l}\text { Direct sequencing of } \\
\text { ZFHX1B revealed } \\
\text { de novo heterozygous } \\
\text { frameshift mutation } \\
\text { nt901delC in exon } 7\end{array}$ & $\begin{array}{l}\text { Not } \\
\text { identified }\end{array}$ & Not stated & $\begin{array}{l}2.27-\mathrm{Mb} \\
\text { deletion at } \\
2 \mathrm{q} 22 \text { including } \\
\text { the entire } \\
\text { ZEB2 gene }\end{array}$ & \\
\hline
\end{tabular}

ID, intellectual disability; ASD, atrial septal defect; VSD, ventricular septal defect; PS, pulmonary stenosis.

et al., 2018]. About $96 \%$ of MWS patients showed abnormal MRI results including abnormalities of the corpus callosum (79.6\%) as the most frequently reported [Garavelli et al., 2017]. Epilepsy, which is considered as one of the most frequent features of MWS occurring in more than $80 \%$ of reported patients, was not a feature in our proband who did not exhibit epileptic fits or abnormal EEG features till he completed his third year of age. The mean onset of epilepsy was reported to be at 27.5 months of age; however, the onset may be delayed to 11 years of age [Ivanovski et al., 2018].

The present patient exhibited severe congenital heart defect in the form of ASD, VSD and pulmonary stenosis. CHD was reported to occur in about $60 \%$ of the patients and most commonly include PDA, VSD and ASD, while pulmonary stenosis occurs in about $20 \%$. Complex cardiac anomalies, however, are much less frequently reported [Adam et al., 2006, Dastot-Le Moal et al., 2007; Ivanovski et al., 2018].
$Z E B 2$, a zinc finger E-box-binding homeobox 2 gene also known as SIP1 (Smad interacting protein 1) or ZF$H X 1 b$ (zinc finger homeobox gene $1 b$ ), is located in cytogenetic band 2q22.3 and is expressed mainly in the development of the nervous system. To date, ZEB2 has been shown to control the formation of the neocortex, hippocampus, corpus callosum, and spinal cord, as well as autonomic and enteric nervous systems [Hegarty et al., 2015].

Gliogenesis and myelinogenesis are also controlled by $Z E B 2$. The various roles of $Z E B 2$ in both neurogenic and gliogenic developments reflect the broad range of target genes and binding partners of ZEB2 as well as the complex regulation of $Z E B 2$ at the genetic level [Cerruti-Mainardi et al., 2004]. ZEB2 mRNA is found in almost every part of the human tissues [Cacheux et al., 2001], which may point to its role in congenital heart defects observed.

The most common molecular defects reported in MWS patients are de novo heterozygous pathogenic 
Table 2. Deletion and duplication involving ZEB2

\begin{tabular}{|c|c|c|c|c|}
\hline Typical face & & Dysmorphic with hyper nasal & & + \\
\hline Long face & - & Wilson syndrome features & - & + \\
\hline eye anomalies & Small eyes & & Medial flare brows & Deep-set wide eyes \\
\hline Low set ears & + & & - & + \\
\hline Pointed chin & - & & - & + \\
\hline Micrognathia & + & & - & + \\
\hline Clenched fist & - & & - & + \\
\hline Mild to moderate ID & Positive & Positive & Positive & Positive \\
\hline Seizures/abn EEG & Negative & Negative & Positive & Negative \\
\hline Congenital heart anomaly & ASD & TOF and $\mathrm{PFO}$ & $\begin{array}{l}\text { ASD,PDA, bicuspid } \\
\text { aortic valve }\end{array}$ & ASD, VSD, PS \\
\hline Hirschsprung disease & Negative & Negative & Positive & Negative \\
\hline Skull anomalies & Scaphocephaly & Negative & Microcephaly & Microcephaly \\
\hline Short stature & Negative & Negative & Positive & Negative \\
\hline Genitourinary anomalies & Small testes & Dysfunctional uterine bleeding & $\begin{array}{l}\text { Neurogenic bladder, } \\
\text { kidney reflux, incontinence }\end{array}$ & Negative \\
\hline Molecular cytogenetic defect & $\begin{array}{l}\text { Triplication/duplication } \\
\text { at } 2 \mathrm{q} 22.2 \mathrm{q} 22.3\end{array}$ & $\begin{array}{l}2.1-\mathrm{Mb} \text { duplication } \\
\text { at } 2 \mathrm{q} 22.3\end{array}$ & $\begin{array}{l}69-\mathrm{kb} \text { duplication } \\
\text { at } 2 \mathrm{q} 22.3\end{array}$ & $\begin{array}{l}2.27-\mathrm{Mb} \text { deletion at } \\
2 \mathrm{q} 22\end{array}$ \\
\hline
\end{tabular}

ASD, atrial septal defect; VSD, ventricular septal defect; PS, pulmonary stenosis; TOF, tetralogy of Fallot; PFO, patent foramen ovale; PDA, patent ductus arteriosus; ID, intellectual disability.

changes in the ZEB2 gene including deletions and other mutations [Ghoumid et al., 2013]. Rarely affected sibs were suggested to result from germline somatic mosaicism [McGaughran et al., 2005; Cecconi et al., 2008].

More than $80 \%$ of the cases with MWS are mainly due to ZEB2 gene mutations. Up till now, 180 distinctive SNVs in the ZEB2 gene have been published including nonsense mutations which account for about $41 \%$ and were mainly present in exon 8 [Dastot-Le Moal et al., 2007]. Small insertions/deletions were detected in $46 \%$ of the patients reported by Ivanovski et al. [2018].

The majority of ZEB2 SNVs cause loss of function by premature termination or large gene deletions [Wakamatsu et al., 2001; Ghoumid et al., 2013; Ivanovski et al., 2018]. A number of cytogenetic abnormalities have been reported in association with MWS including chromosome deletions or translocations involving the breakpoint 2q22.

Patients with normal karyotypes have been also diagnosed during systematic CMA screening due to dysmorphic features and ID or epilepsy and brain malformations. Most reported chromosomal rearrangements resulted in complete ZEB2 deletion; however, intronic disruption by the translocation breakpoint without presence of a deletion were sporadically reported [Cacheux et al., 2001; Engenheiro et al., 2008].

Similar to our patient, Engenheiro et al. [2008] reported a patient with a normal karyotype diagnosed as MWS by array $\mathrm{CGH}$. The patient revealed $0.6-\mathrm{Mb}$ interstitial microdeletion at chromosome $2 \mathrm{q} 22$. The deleted region 
included the entire ZEB2 gene and the authors suggested that MWS may be underdiagnosed and should be considered in patients with ID, dysmorphic features, epilepsy and $\mathrm{CHD}$, especially with pulmonary valve stenosis or pulmonary artery sling.

In a large cohort reported by Ivanovski et al. [2018], chromosome deletions were reported in $11.5 \%$ of the patients ranging in length from few kilobases to $16.7 \mathrm{Mb}$, mostly involving the entire ZEB2 gene or its first exons. Others encompassed exons 5-8, leading to an altered reading frame. Rare variants included 3' UTR region deletion, possibly altering protein synthesis or regulation, and an intronic change resulting in altered splice acceptor site of exon 2 and expected to produce a smaller protein with abnormal function [Zweier et al., 2006].

Using CMA, a de novo novel duplication of $69 \mathrm{~kb}$ encompassing exons 1 and 2 of the ZEB2 gene was first reported by Baxter et al. [2017] in a 14-year-old female clinically diagnosed to have MWS. She suffered from microcephaly, seizures, distinctive facies, and HSCR. Yuan et al. [2015] also reported a boy showing a de novo $2.9-\mathrm{Mb}$ triplication/duplication encompassing chromosome $2 \mathrm{q} 22.3$ that covered the entire $Z E B 2$ gene in addition to GTDC1, TEX41, and part of ARHGAP15. The patient presented with hypotonia, dysmorphic facial features in form of small eyes, flat nasal bridge and flat facial profile that were considerably different than those present in MWS, as well as ASD.

Similarly, Mak et al. [2016] reported an overlapping $2.1-\mathrm{Mb}$ region duplication that fully comprised $Z E B 2$ as well as GTDC1, TEX4 in addition to part of ARHGAP15. The patient suffered from mild ID, distinctive hyper nasal voice, and dysmorphic facial features that also did not fit those of MWS patients.

The studies conducted by Baxter et al. [2017], Yuan et al. [2015], and Mak et al. [2016] indicate that duplication of the ZEB2 is of clinical significance and may result in MWS or other pathogenic consequences, and that the ZEB2 gene is likely to be a dosage-sensitive gene, and its duplication/triplication may cause gene disruption or even novel function due to genetic fusion as shown in Table 2.

The deleted region in our patient included, in addition to the ZEB2 gene, GTDC1 and ARHGAP15 which were duplicated in both patients of Yuan et al. [2015] and Mak et al. [2016]. The presence of CHD in both reports and the severe degree of cardiac anomalies in our patient indicate the crucial role of $Z E B 2$ dosage in cardiac development and the possible role of other associated gene abnormalities in augmenting this effect.
Other genes found to be deleted by CMA in the 2q22.2q22.3 region included HSR, VCRL2, TSE2, CMD1H, COPD, CHDS2, GTDC1, and ARHGAP15. Abnormalities in the GTDC1, ARHGAP15, TSE2, and $M A F D 5$ genes showed no significant phenotype correlation, which proves that the $Z E B 2$ gene is the main gene responsible for the patient's phenotype.

In conclusion, we report the first MWS patient in Egypt diagnosed using CMA which highlights the significance of molecular cytogenetic techniques in detection of microdeletion/microduplication syndromes and its importance as a screening test in cases presenting with $\mathrm{CHD}$ and extracardiac manifestations with facial dysmorphism. It is also recommended to include the ZEB2 locus in the MLPA microdeletion probes.

MWS is a rare syndrome showing a wide spectrum of dysmorphic features and few atypical presentations making it a rather challenging diagnosis for clinical geneticists; however it should be suspected in patients presenting with distinctive facial dysmorphism, severely impaired speech, developmental delay, ID, seizures or brain malformations, HSCR, in addition to congenital heart anomalies, especially those involving the pulmonary arteries or pulmonary valves.

\section{Acknowledgement}

The authors acknowledge the patient and his parents for participating in this study.

\section{Statement of Ethics}

The study was conducted according to the guidelines of the Medical Research Ethics Committee of the National Research Centre based on the World Medical Association Declaration of Helsinki, and an informed consent has been taken from the patient's guardians.

\section{Conflict of Interest Statement}

The authors have no conflicts of interest to declare.

\section{Funding Sources}

This study was supported by the Science and Technology Development Fund (STDF): Grant Project number 5253, Centre of Scientific Excellence for Human Genetics.
Refaat/Helmy/Elawady/El Ruby/Kamel/ Mekkawy/Ashaat/Eid/Mohamed/Rady 


\section{Author Contributions}

All authors have made substantial contributions to the conception of the work, analysis and interpretation of data, participated in revising the work, responsible for all aspects of the work in ensuring that questions related to the accuracy of the work are appropriately investigated, and they all approved the final version to be published.

\section{References}

Abdalla EM, Zayed LH. Mowat-Wilson syndrome: deafness in the first Egyptian case who was conceived by intracytoplasmic sperm injection. J Child Neurol. 2014;29(12):NP16870.

Adam MP, Schelley S, Gallagher R, Brady AN Barr K, Blumberg B, et al. Clinical features and management issues in Mowat-Wilson syndrome. Am J Med Genet A. 2006;140(24): 2730-41.

Amiel J, Espinosa-Parrilla Y, Steffann J, Gosset P, Pelet A, Prieur M, et al. Large-scale deletions and SMADIP1 truncating mutations in syndromic Hirschsprung disease with involvement of midline structures. Am J Hum Genet. 2002;69(6):1370-7.

Baxter AL, Vivian JL, Hagelstrom RT, Hossain W, Golden WL, Wassman ER, et al. A Novel Partial Duplication of ZEB2 and Review of ZEB2 Involvement in Mowat-Wilson Syndrome. Mol Syndromol. 2017;8(4):211-8.

Cacheux V, Dastot-Le Moal F, Kääriäinen $\mathrm{H}$ Bondurand N, Rintala R, Boissier B, et al. Loss-of-function mutations in SIP1 Smad interacting protein 1 result in a syndromic Hirschsprung disease. Hum Mol Genet. 2001; 10(14):1503-10.

Cecconi M, Forzano F, Garavelli L, Pantaleoni C, Grasso M, Dagna Bricarelli F, et al. Recurrence of Mowat-Wilson syndrome in siblings with a novel mutation in the ZEB2 gene. Am J Med Genet A. 2008;146A(23):3095-9.

Cerruti-Mainardi P, Pastore G, Zweier C, Rauch A. Mowat-Wilson sindrome and mutation in the zinc finger homeo box $1 \mathrm{~B}$ gene: a well defined clinical entity. J Med Genet. 2004;41: e16.

Dastot-Le Moal F, Wilson M, Mowat D, Collot N, Niel F, Goossens M. ZFHX1B mutations in patients with Mowat-Wilson syndrome. Hum Mutat. 2007;28(4):313-21.

Engenheiro E, Møller RS, Pinto M, Soares G, Nikanorova M, Carreira IM, et al. Mowat-Wilson syndrome: an underdiagnosed syndrome?. Clin Genet. 2008;73(6):579-84.

Garavelli L, Mainardi PC. Mowat-Wilson syndrome. Orphanet J Rare Dis. 2007;2(2):42.

Garavelli L, Donadio A, Zanacca C, Banchini G, Della GiustinaE, Bertani G, et al.Hirschsprung disease, mental retardation, characteristic facial features, and mutation in the gene ZFHX1B (SIP1): confirmation of the MowatWilson syndrome. Am J Med Genet A. 2003; $116 \mathrm{~A}(4): 385-8$.
Garavelli L, Zollino M, Mainardi PC, Gurrieri F, Rivieri F, Soli F, et al. Mowat-Wilson syndrome: facial phenotype changing with age: study of 19 Italian patients and review of the literature. Am J Med Genet A. 2009;149A(3): 417-26.

Garavelli L, Ivanovski I, Caraffi SG, Santodirocco D, Pollazzon M, Cordelli DM, et al. Neuroimaging findings in Mowat-Wilson syndrome: a study of 54 patients. Genet Med. 2017;19(6): 691-700.

Ghoumid J, Drevillon L, Alavi-Naini SM, Bondurand $\mathrm{N}$, Rio $\mathrm{M}$, Briand-Suleau A, et al. ZEB2 zinc-finger missense mutations lead to hypomorphic alleles and a mild Mowat-Wilson syndrome. Hum Mol Genet. 2013;22(13):2652-61.

Hegarty SV, Sullivan AM, O'Keeffe GW. Zeb2: A multifunctional regulator of nervous system development. Prog Neurobiol. 2015;132:8195.

ISCN 2016. An International System for Human Cytogenomic Nomenclature. Cytogenet Genome Res. 2016;149:1-140.

Ishihara N, Shimada A, Kato J, Niimi N, Tanaka S, Miura K, et al. Variations in aganglionic segment length of the enteric neural plexus in Mowat-Wilson syndrome. J Pediatr Surg. 2005;40(9):1411-9.

Ivanovski I, Djuric O, Caraffi SG, Santodirocco D, Pollazzon M, Rosato S, et al. Phenotype and genotype of 87 patients with Mowat-Wilson syndrome and recommendations for care. Genet Med. 2018;20(9):965-75.

Lurie IW, Supovitz KR, Rosenblum-Vos LS, Wulfsberg EA. Phenotypic variability of $\operatorname{del}(2)$ (q22-q23): report of a case with a review of the literature. Genet Couns. 1994:5:11-4.

Mak CCY, Chow PC, Liu APY, Chan KYK, Chu YWY, Mok GTK, et al. De novo large rare copy-number variations contribute to conotruncal heart disease in Chinese patients. NPJ Genom Med. 2016;1:16033.

McGaughran J, Sinnott S, Dastot-Le Moal F, Wilson M, Mowat D, Sutton B, et al. Recurrence of Mowat-Wilson syndrome in siblings with the same proven mutation. Am J Med Genet A. $2005 ; 137 \mathrm{~A}(3): 302-4$.

Mowat D, Wilson M. Mowat-Wilson syndrome. Chapter 35. 3rd ed. In: Cassidy SB, Allanson JE, editors. Management of Genetic Syndromes. Hoboken: Wiley-Blackwel; 2010.

Mowat DR, Croaker GDH, Cass DT, Kerr BA Chaitow J, Adés LC, et al. Hirschsprung disease, microcephaly, mental retardation, and characteristic facial features: delineation of a new syndrome and identification of a locus at chromosome 2q22-q23. J Med Genet. 1998; 35:617-23.

Mowat DR, Wilson MJ, Goossens M. MowatWilson syndrome. J MED Genet. 2003;40(5): 305-10.

Paz JA, Kim CA, Goossens M, Giurgea I, MarquesDias MJ. Mowat-Wilson syndrome: neurological and molecular study in seven patients Arq Neuropsiquiatr. 2015;73(1):12-7.

Verma RS, Babu A. Human chromosomes: Principles and techniques. 2nd ed. New York: McGraw-Hill; 1995.

Wakamatsu N, Yamada Y, Yamada K, Ono T, Nomura $\mathrm{N}$, Taniguchi $\mathrm{H}$, et al. Mutations in SIP1, encoding Smad interacting protein-1, cause a form of Hirschsprung disease. Nat Genet. 2001;27(4):369-70.

Wilson M, Mowat D, Dastot-Le Moal F, Cacheux V, Kääriäinen H, Cass D, et al. Further delineation of the phenotype associated with heterozygous mutations in ZFHX1B. Am J Med Genet A. 2003;119A(3):257-65.

Yamada K, Yamada Y, Nomura N, Miura K, Wakako R, Hayakawa C, et al. Nonsense and frameshift mutations in ZFHX1B, encoding Smad-interacting protein 1 , cause a complex developmental disorder with a great variety of clinical features. Am J Hum Genet. 2001; 69(6):1178-85

Yoneda M, Fujita T, Yamada Y, Yamada K, Fujii A, Inagaki T, et al. Late infantile Hirschsprung disease-mental retardation syndrome with a 3-bp deletion in ZFHX1B. Neurology. 2002; 59(10):1637-40.

Yuan H, Zhang L, Chen M, Zhu J, Meng Z, Liang L. A de novo triplication on $2 \mathrm{q} 22.3$ including the entire ZEB2 gene associated with global developmental delay, multiple congenital anomalies and behavioral abnormalities. $\mathrm{Mol}$ Cytogenet. 2015;8:99.

Zweier C, Albrecht B, Mitulla B, Behrens R, Beese M, Gillessen-Kaesbach G, et al. "Mowat-Wilson"syndromewith and withoutHirschsprung disease is a distinct, recognizable multiple congenital anomalies-mental retardation syndrome caused by mutations in the zinc finger homeo box 1B gene. Am J Med Genet. 2002;108(3):177-81.

Zweier C, Horn D, Kraus C, Rauch A. Atypical ZFHX1B mutation associated with a mild Mowat-Wilson syndrome phenotype. Am J Med Genet A. 2006;140(8):869-72.
Mowat-Wilson Syndrome Patient due to Interstitial Deletion Involving ZEB2
Mol Syndromol 2021;12:87-95

DOI: $10.1159 / 000513313$ 